\title{
Economic Evaluation of a Pharmaceutical Care Program for Elderly Diabetic and Hypertensive Patients in Primary Health Care: A 36-Month Randomized Controlled Clinical Trial
}

\author{
Paulo Roque Obreli-Neto, PhD; Srecko Marusic, MD; Camilo Molino Guidoni, PhD; \\ André de Oliveira Baldoni, PhD; Rogério Dias Renovato, PhD; Diogo Pilger, PhD; \\ Roberto Kenji Nakamura Cuman, PhD; and Leonardo Régis Leira Pereira, PhD
}

\begin{abstract}
BACKGROUND: Most diabetic and hypertensive patients, principally the elderly, do not achieve adequate disease control and consume $5 \%-15 \%$ of annual health care budgets. Previous studies verified that pharmaceutical care is useful for achieving adequate disease control in diabetes and hypertension.
\end{abstract}

OBJECTIVE: To evaluate the economic cost and the incremental costeffectiveness ratio (ICER) per quality-adjusted life-year (QALY) of pharmaceutical care in the management of diabetes and hypertension in elderly patients in a primary public health care system in a developing country.

METHODS: A 36-month randomized controlled clinical trial was performed with 200 patients who were divided into a control group $(n=100)$ and an intervention group $(n=100)$. The control group received the usual care offered by the Primary Health Care Unit (medical and nurse consultations). The intervention group received the usual care plus a pharmaceutical care intervention. The intervention and control groups were compared with regard to the direct costs of health services (i.e., general practitioner, specialist, nurse, and pharmacist appointments; emergency room visits; and drug therapy costs) and the ICER per QALY. These evaluations used the health system perspective.

RESULTS: No statistically significant difference was found between the intervention and control groups in total direct health care costs (\$281.97 $\pm \$ 49.73$ per patient vs. $\$ 212.28 \pm \$ 43.49$ per patient, respectively; $P=0.089$ ); pharmaceutical care added incremental costs of $\$ 69.60$ $( \pm \$ 7.90)$ per patient. The ICER per QALY was $\$ 53.50$ (95\% Cl $=\$ 51.60$ $\$ 54.00$; monetary amounts are given in U.S. dollars). Every clinical parameter evaluated improved for the pharmaceutical care group, whereas these clinical parameters remained unchanged in the usual care group. The difference in differences (DID) tests indicated that for each clinical parameter, the patients in the intervention group improved more from pre to post than the control group $(P<0.001)$.

CONCLUSIONS: While pharmaceutical care did not significantly increase total direct health care costs, significantly improved health outcomes were seen. The mean ICER per QALY gained suggests a favorable cost-effectiveness.

J Manag Care Pharm. 2015;21(1):66-75

Copyright $\odot 2015$, Academy of Managed Care Pharmacy. All rights reserved.

\section{What is already known about this subject}

Diabetes mellitus and hypertension have been recognized as major public health problems, principally in the elderly population, with far reaching consequences not just for its adverse impact on the health of the individuals, but also for the economic burden it places on the health care system, consuming 5\%-15\% of annual health care budgets.

The economic burden of diabetes mellitus and hypertension is directly influenced by the high rates of patients who do not achieve adequate disease control, which indicate that there is a need to explore alternative strategies to address these public health problems.

Pharmaceutical care programs have been found useful in helping elderly diabetic and hypertensive patients achieve adequate disease control (improvement on blood pressure, blood glucose, and lipid levels have been reported).

\section{What this study adds}

This is the first long-term (36 months) controlled prospective clinical trial performed in a primary health care setting in a developing country that assessed the economic cost and costeffectiveness of a pharmaceutical care program (using a standardized method) for elderly diabetic and hypertensive patients.

The pharmaceutical care program added insignificant expenditures to overall health care costs, while showing improvements in all clinical outcomes measured (systolic blood pressure, diastolic blood pressure, fasting blood glucose, hemoglobin Alc, lowdensity lipoprotein cholesterol, and the 10-year risk assessment for coronary heart disease risk)

$\mathrm{D}$ iabetes mellitus and hypertension are currently important public health challenges worldwide. The prevalence of diabetes mellitus worldwide was estimated to be more than 371 million individuals in 2012, and the prevalence of hypertension worldwide was estimated to be 972 million individuals in 2000 $0^{1,2}$ By 2025, the number of individuals with diabetes is predicted to increase by approximately $35 \%$, and the number of individuals with hypertension is predicted 
to increase by approximately $60 \%$, reaching a total of 500 million and 1.56 billion individuals, respectively.1,2

Data from the National Health and Nutrition Examination Survey from $2007-2010$ showed that more than $40 \%$ of patients with diabetes mellitus do not achieve adequate disease control. ${ }^{3}$ More than $60 \%$ of patients with hypertension do not achieve adequate disease control., ${ }^{4,5}$ The high prevalence of patients who do not achieve adequate disease control increases the occurrence of negative clinical outcomes, such as hospitalizations, disease complications (e.g., retinopathy, nephropathy, neuropathy, stroke, and acute myocardial infarction), earlier retirement caused by disease complications, and death. ${ }^{6-11}$

The negative clinical outcomes of diabetes mellitus and hypertension cause increases in direct and indirect economic costs to society. Diabetes mellitus and hypertension consume $5 \%-15 \%$ of annual health care budgets. In 2012, $\$ 471$ billion (in U.S. dollars) were spent worldwide because of diabetes mellitus, and in 2009, hypertension cost the United States $\$ 73.4$ billion. ${ }^{1,12}$ Most cases of diabetes mellitus and hypertension involve elderly patients, so the economic burden of these diseases is expected to be greater in elderly patients., ${ }^{1,2}$

Given the elevated prevalence of these 2 diseases, the number of patients who do not reach adequate disease control, and the economic cost of diabetes mellitus and hypertension, alternative strategies need to be explored to address the economic burden of these diseases in the elderly population, especially at the primary health care level, which is responsible for most of the care provided for diabetic and hypertensive patients.

The intervention of the pharmacist as a member of the health care team in the patient care process by way of pharmaceutical care-defined by Hepler and Strand (1990) as "the responsible provision of drug therapy for the purpose of achieving definite outcomes that improve a patient's quality of life"13 — can be an efficient strategy to reduce the economic burden of diabetes mellitus and hypertension. ${ }^{14-17}$ Previous studies have verified that pharmaceutical care is useful for achieving adequate disease control for diabetes mellitus and hypertension in elderly patients. ${ }^{18-22}$

However, to the authors' knowledge, most of the published studies have focused on the clinical outcomes of pharmaceutical care, and few studies have reported the economic cost and cost-effectiveness of pharmaceutical care. The few studies that evaluated the economic cost and cost-effectiveness of pharmaceutical care for diabetes and hypertension management were of short duration; ${ }^{14,15,17,23,24}$ were performed in developed countries: $^{14-17}$ and did not focus on the elderly population. ${ }^{14-17,23,24}$ Thus, we conducted a long-term (36 months) study that focused on the elderly population and evaluated the economic cost and cost-effectiveness of pharmaceutical care in the management of diabetes and hypertension in the primary public health care system in a developing country.
The purpose of this study was to evaluate the economic cost and cost-effectiveness of a pharmaceutical care program in the management of diabetes and hypertension in elderly patients compared with the usual care provided in a primary public health care facility in Brazil. This study hypothesized that (a) the addition of pharmaceutical care in the health care team did not increase significantly the total direct health care cost of elderly diabetic and hypertensive patients and (b) the addition of pharmaceutical care in the health care team improved the effectiveness of the care provided to elderly diabetic and hypertensive patients at the primary health care level.

\section{Methods}

\section{Study Design and Setting}

A randomized, controlled, longitudinal, clinical trial was conducted from October 2006 to October 2009 in a Brazilian public Primary Health Care Unit (PHCU) located in the municipality of Salto Grande, Sao Paulo state. Brazil's Sistema Único de Saúde (SUS) is a universal, publicly funded, rights-based public health care system. The SUS states that every citizen, regardless of economic and social condition, has access to all levels of health care (i.e., primary, secondary, and tertiary), including medications. ${ }^{25,26}$ Primary care offered to outpatients in PHCUs includes health education, prevention, surveys of the spread of disease, and drug dispensation. Family physicians, general practitioners, and nurses provide primary health care services, including consultations, exams, education groups, and vaccinations. Pharmacists work primarily in administrative services, such as the acquisition and inventory control of drugs, with little clinical activity directed at the patient. The primary care level of SUS is the sole choice for access to health care for approximately $70 \%$ of the Brazilian population, which does not have the financial resources to pay directly for private health care services or drugs.

\section{Study Subjects}

The patients who were eligible for inclusion in our study were aged $\geq 60$ years; diagnosed with diabetes or hypertension according to Brazilian national consensus guidelines, ${ }^{27,28}$ under drug treatment for diabetes or hypertension; regularly participated in medical, nursing, and educational activities offered at the PHCU; and had up-to-date results for their routine physical and laboratory tests (no more than 30 days prior to baseline measurements). The exclusion criteria included difficulties going to the PHCU, speaking difficulties that would interfere with participation in the study, and patients who were already followed by a clinical pharmacist.

Eligible patients were identified using an electronic database available in the PHCU (Cetil). The information available in this electronic database includes patient identification (medical record number, name, sex, date of birth, and address); clinical information (diagnosed diseases, results and dates of clinical 
and laboratory exams, dates and description of consultations, and attendance frequency in educational groups); and drug therapy information (name of the drugs dispensed, name of prescriber, date of dispensation, and amount dispensed).

\section{Sample Size and Randomization}

A total of 397 patients who met the inclusion criteria and had no exclusion criteria present were identified for inclusion in the study. A sample size of 191 patients was necessary to perform the study with a margin of error of $5 \%$ and confidence interval (CI) of $95 \%$. The sample size of the trial was calculated to detect a 10\% reduction in serum low-density lipoprotein (LDL) cholesterol, since it is the major lipid marker of coronary heart disease. It was estimated that 95 patients would be required in each group for a 2 -tailed $\alpha$ of 0.05 and a $1-\beta$ of $80 \%$. Based on these data, to ensure sufficient statistical power and account for dropouts during the study, a target sample size of 200 patients was assumed. Eligible patients who were willing to participate in the study and provided oral and written consent were randomized into 2 proportional groups: a control group $(n=100$ patients) and an intervention group $(\mathrm{n}=100$ patients).

JMP 8.0.1 software (SAS Institute, Inc., Cary, NC) provided computer-generated random sequences (100 patients each in the intervention and control groups) according to the medical record numbers of the 200 patients selected.

\section{Description of Interventions}

All patients in the control and intervention groups were enrolled at the beginning of the study (October 1, 2006, to October 30, 2006) and were followed for 36 months.

Patients who enrolled in the control group received the usual care offered at the PHCU, which consisted of appointments with general practitioners every 3 months and with nurses every month. All of the procedures administered were recorded in the patient records and consisted of alterations in prescribed drugs, requests for laboratory exams, general information about patient health, and specialist referrals. Patients received their prescription services without any pharmaceutical care intervention.

Patients who were randomized to the intervention group received pharmaceutical care in addition to the usual care offered. The pharmaceutical care intervention consisted of individual follow-ups according to the Pharmacotherapy Workup (developed at the University of Minnesota in the United States $^{29}$ ) and educational group activities. The Pharmacotherapy Workup was performed by 4 previously trained pharmacists. The training lasted 20 hours and focused on the Pharmacotherapy Workup process. For patients in the intervention group, the frequency of visits was once every 6 months. This schedule was adopted so that the visits did not interfere with the routine activities of the PHCU pharmacist staff. During the Pharmacotherapy Workup, interventions were provided in order to guarantee a high rate of compliance with the pharmacotherapy. These interventions included the assessment of noncompliance, discussions with patients and family about the role of medication in their health status (including patients' active participation in choosing their drug treatment), suggestions to physicians regarding new drug regimens (considering the patients' medication experience), orientation with regard to the proper use of drugs, and the preparation of special packages to provide a visual reminder that a medication was taken.

The pharmaceutical care program was developed individually according to the individual needs of patients and knowledge of their clinical conditions and drug therapy. Data concerning each patient's reason for the encounter, demographic information, pharmacotherapy history, medication experience, and other clinical information were obtained during the assessment and recorded in the patient's medical records. After assessing whether the patient's drug-related needs were being met and whether any drug therapy problems were present, the pharmacists developed individual care plans for the patients, with patients participating actively in the formulation of their plans.

The first step of the care plan was to determine the goals of therapy (e.g., parameters, values, and time frames), which were determined by consensus between the pharmacist and patient. The pharmacists performed verbal and written orientations related to controlling the disease, compliance with therapeutic and nontherapeutic treatments, appropriate nutrition, and the correct use of drugs. The pharmacists also worked in association with other health care professionals for additional interventions, such as the adjustment of drug dosages, modification of drug therapy (addition or withdrawal), modification of diet plans, and practice of physical activities. In the follow-up evaluation, the patient outcomes related to the individual desired goals of therapy were evaluated, and the patients were reassessed to determine whether any new drug therapy problems developed. Educational group activities were also organized once every 6 months, with groups of 20 patients. During these activities, such subjects as adherence, the dangers of self-medication, and the correct storage of medicines were discussed.

\section{Outcome Evaluation}

For the analysis of economic costs, we compared the intervention and control groups with regard to the following direct health care costs during the 36-month study period: general practitioner appointments, specialist appointments (referrals to cardiologists and endocrinologists), nurse appointments, pharmacist appointments (only for the intervention group), emergency room visits, and drug therapy costs. The total direct health care costs consisted of aggregate managed care costs for any health care service provided plus drug costs for each patient. ${ }^{14}$ The costs of general practitioner appointments, specialist appointments, nurse appointments, and pharmacist 


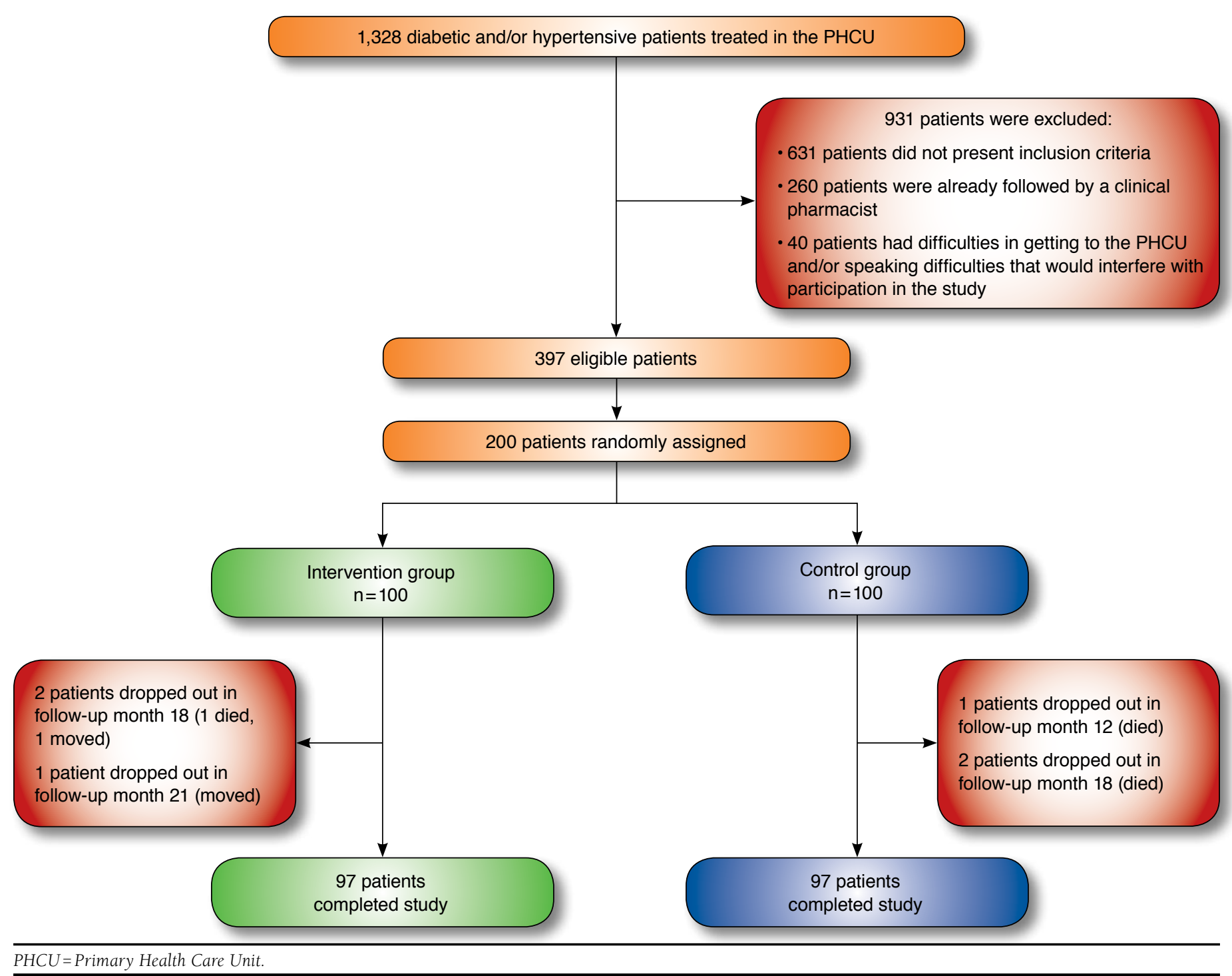

appointments per patient during the study period were based on the salary of the provider (these data were obtained from the Municipal Department of Public Health of Salto Grande). The costs of emergency room visits per patient during the study period were obtained from the Outpatient Information System of the Brazilian Public Health System. To evaluate the costs of drug therapy per patient, we calculated the price for the amount of drugs dispensed per patient during the study period (the purchasing price of the drugs was obtained from the Municipal Department of Public Health of Salto Grande).

For analysis of the cost-effectiveness of the pharmaceutical care, we estimated the incremental cost-effectiveness ratio (ICER) per quality-adjusted life-year (QALY). The ICER per
QALY was calculated as the difference in the total direct health care costs between the intervention and control groups divided by the difference in QALY between the intervention and control groups. Healthy utility values between 0 (decreased) and 1 (perfect health) were used to estimate QALYs for each disease state. Utility levels were 0.690 for blindness, 0.610 for end-stage renal disease, 0.800 for lower extremity amputation, 0.500 for stroke, 0.880 myocardial infarction, 0.947 for angina, and utility levels for all other health states were set to $1 .^{30-34}$

\section{Data Analysis}

The data were entered into a Microsoft Excel database and imported into the JMP software package. Before selecting 
Economic Evaluation of a Pharmaceutical Care Program for Elderly Diabetic and Hypertensive Patients in Primary Health Care: A 36-Month Randomized Controlled Clinical Trial

TABLE 1 General Characteristics of Study Participants at Baseline

\begin{tabular}{|c|c|c|c|c|c|}
\hline \multirow{2}{*}{$\begin{array}{l}\text { Variable } \\
\text { Female gender, n (\%) }\end{array}$} & \multicolumn{2}{|c|}{ Intervention Group $(\mathrm{n}=97)$} & \multicolumn{2}{|c|}{ Control Group $(\mathrm{n}=97)$} & \multirow{2}{*}{$\begin{array}{c}P \text { Value }{ }^{\mathrm{a}, \mathrm{b}} \\
0.882 \\
\end{array}$} \\
\hline & 61.0 & $(62.9)$ & 60.0 & $(61.8)$ & \\
\hline Mean age, years (SD) & 65.3 & $(5.8)$ & 65.3 & $(5.8)$ & 0.990 \\
\hline Mean monthly family income, \$ (SD) & 314.9 & $(99.1)$ & 317.8 & $(101.8)$ & 0.320 \\
\hline Incomplete elementary school, n (\%) & 76.0 & $(78.4)$ & 75.0 & $(77.4)$ & 0.926 \\
\hline Mean SBP, mmHg (SD) & 156.7 & $(21.8)$ & 155.9 & $(20.8)$ & 0.788 \\
\hline Mean DBP, mmHg (SD) & 106.6 & $(17.7)$ & 108.7 & $(16.9)$ & 0.363 \\
\hline Mean fasting glucose, mg/dL (SD) & 135.1 & $(55.6)$ & 135.8 & $(55.4)$ & 0.932 \\
\hline Mean hemoglobin Alc, \% (SD)c & 7.7 & $(0.5)$ & 7.7 & $(0.5)$ & 0.691 \\
\hline Mean triglycerides, mg/dL (SD) & 206.0 & $(134.8)$ & 206.5 & $(134.6)$ & 0.977 \\
\hline Mean LDL cholesterol, mg/dL (SD) & 112.4 & $(12.7)$ & 112.1 & $(12.7)$ & 0.902 \\
\hline Mean HDL cholesterol, mg/dL (SD) & 55.5 & $(8.5)$ & 54.9 & $(6.6)$ & 0.511 \\
\hline Mean total cholesterol, mg/dL (SD) & 202.5 & $(35.7)$ & 202.0 & $(35.4)$ & 0.915 \\
\hline Mean 10-year risk assessment for coronary heart disease, \% (SD)d & 6.8 & $(4.5)$ & 6.9 & $(4.5)$ & 0.895 \\
\hline Mean diagnosed diseases, $\mathrm{n}(\mathrm{SD})$ & 2.4 & $(1.3)$ & 2.4 & $(1.3)$ & 0.986 \\
\hline Patients diagnosed with hypertension, $\mathrm{n}(\%)^{\mathrm{d}, \mathrm{e}}$ & 46.0 & $(47.4)$ & 44.0 & $(45.4)$ & 0.776 \\
\hline Patients diagnosed with diabetes, $\mathrm{n}(\%)^{\mathrm{e}}$ & 17.0 & $(17.5)$ & 18.0 & $(18.5)$ & 0.854 \\
\hline Patients presenting with diabetes and hypertension, $\mathrm{n}(\%)$ & 34.0 & $(35.1)$ & 35.0 & $(36.1)$ & 0.882 \\
\hline Mean number of drugs for chronic use, $\mathrm{n}$ (SD) & 3.3 & $(1.7)$ & 3.3 & $(1.7)$ & 0.174 \\
\hline \multicolumn{6}{|c|}{$\begin{array}{l}\text { Note: Monetary values are presented in U.S. dollars. } \\
\text { aThe } \chi^{2} \text { test and independent-sample Student } t \text {-test were used as appropriate. } \\
{ }^{2} P<0.05 \text { was considered statistically significant. } \\
\text { cOnly patients with a diagnosis of diabetes were subjected to this exam. } \\
\text { d10-year risk assessment for coronary heart disease was performed using the Framingham scoring method. }{ }^{32} \\
\text { ePatients presenting with hypertension or diabetes. } \\
D B P=\text { diastolic blood pressure; } H D L=\text { high-density lipoprotein; } L D L=l o w \text {-density lipoprotein; } m g / d L=\text { milligrams per deciliter; } m m H g=\text { millimeter of mercury; } \\
S B P=\text { systolic blood pressure; } S D=\text { standard deviation. }\end{array}$} \\
\hline
\end{tabular}

the tests, the data were tested for a normal distribution. For comparisons between the intervention and control groups, we used the $\chi^{2}$ test and independent-sample Student t-test as appropriate. For comparisons between the baseline and endpoint values in the control group and the intervention group, difference in differences (DID) tests were used. A $P$ value $<0.05$ was considered statistically significant. The data were analyzed using JMP software.

\section{Ethical Considerations}

Approval for this project was obtained from the Internal Review Board at the State University of Maringá.

\section{Results}

\section{Baseline Characteristics}

A total of 194 individuals completed the study (97 patients in each group; Figure 1). The intervention and control groups were well balanced at baseline with regard to sociodemographic, clinical, and drug therapy characteristics (Table 1).

\section{Health Care Utilization}

The mean number (standard deviation [SD]) of general practitioner appointments and specialist appointments was significantly higher for the intervention group than the control group.
The control group had a significantly higher mean number of emergency room visits than the intervention group. No significant differences were found between groups in the mean number of nurse appointments and drugs used per patient (Table 2).

No patient was hospitalized during the study period for reasons related to diabetes or hypertension. Six emergency room visits were reported in the intervention group (each visit was for a different patient), and 14 emergency room visits were reported in the control group (1 patient visited the emergency room 3 times, and the other 11 visits were for different patients).

\section{Direct Health Care Costs}

Patients enrolled in the intervention group had a statistically significant higher cost related to general practitioner appointments, specialist appointments, and pharmacist appointments. Patients enrolled in the control group had a significantly higher cost related to emergency room visits. No statistically significant differences were observed in the mean costs related to nurse appointments and drug therapy costs. Despite the differences in some direct health care costs, we did not find significant difference between the intervention and control groups in total direct health care costs (Table 3). 
Economic Evaluation of a Pharmaceutical Care Program for Elderly Diabetic and Hypertensive Patients in Primary Health Care: A 36-Month Randomized Controlled Clinical Trial

TABLE 2 Health Care Utilization During Study Period (36 Months)

\begin{tabular}{|c|c|c|c|c|c|}
\hline \multirow{2}{*}{$\begin{array}{l}\text { Variable } \\
\text { Mean general practitioner appointments per patient, } n \text { (SD) }\end{array}$} & \multicolumn{2}{|c|}{ Intervention Group $(n=97)$} & \multicolumn{2}{|c|}{ Control Group $(n=97)$} & \multirow{2}{*}{$\frac{P \text { Value }{ }^{\mathrm{a}, \mathrm{b}}}{<0.001}$} \\
\hline & 5.5 & $(1.5)$ & 4.2 & $(0.7)$ & \\
\hline Mean specialist appointments per patient, $\mathrm{n}$ (SD) & 0.2 & $(0.4)$ & 0.1 & $(0.3)$ & 0.011 \\
\hline Mean nurse appointments per patient, $\mathrm{n}$ (SD) & 12.1 & $(0.3)$ & 12.0 & $(0.2)$ & 0.758 \\
\hline Mean pharmacist appointments per patient, $\mathrm{n}(\mathrm{SD})^{\mathrm{c}}$ & 2.1 & $(0.1)$ & & & \\
\hline Mean emergency department visits per patient, $\mathrm{n}$ (SD) & 0.0 & $(0.2)$ & 0.1 & $(0.4)$ & $<0.001$ \\
\hline Mean drugs used per patient, $n(S D) d$ & 4.6 & $(0.8)$ & 3.5 & $(1.4)$ & 0.092 \\
\hline \multicolumn{6}{|c|}{$\begin{array}{l}\text { aIndependent-sample Student t-tests were used. } \\
b_{P}<0.05 \text { was considered statistically significant. } \\
\text { 'Patients enrolled in the control group did not receive pharmacist appointments. } \\
{ }^{T} \text { The mean number of drugs was based on the drugs used in the last month of the study. } \\
S D=\text { standard deviation. }\end{array}$} \\
\hline
\end{tabular}

\section{Clinical Effectiveness}

Significant reductions $(P<0.05)$, indicating clinical improvements, in the mean values (baseline vs. end of study; $95 \% \mathrm{CI}$ ) were found for every clinical outcome assessed for the intervention group. The proportion of intervention group patients achieving clinical outcome ranged from $26.8 \%$ at baseline to $86.6 \%$ after 36 months for systolic blood pressure (SBP) levels; from $27.9 \%$ at baseline to $84.8 \%$ after 36 months for diastolic blood pressure (DBP) levels; from $29.9 \%$ at baseline to $70.1 \%$ after 36 months for fasting blood glucose levels; from 3.3\% at baseline to $63.3 \%$ after 36 months for hemoglobin Alc; and from $59.8 \%$ at baseline to $80.4 \%$ after 36 months for LDL cholesterol. No significant changes were found in the control group. The proportion of control group patients achieving the clinical outcome ranged from $26.8 \%$ at baseline to $30.9 \%$ after 36 months for SBP levels; from $29.9 \%$ at baseline to $27.4 \%$ after 36 months for DBP levels; from $30.9 \%$ at baseline to $27.8 \%$ after 36 months for fasting blood glucose levels; from 3.3\% at baseline to $3.3 \%$ after 36 months for Alc; and from 63.9\% at baseline to $63.9 \%$ after 36 months for LDL cholesterol. Between-group comparisons of clinical pre-post outcomes (i.e., DID comparisons) showed that the intervention group had significant differences for every clinical outcome evaluated (Table 4).

\section{Incremental Cost-Effectiveness Ratio per Quality-Adjusted Life-Year}

On average, pharmaceutical care costs for this intervention was estimated at $\$ 69.60$ (95\% CI $=\$ 57.40-\$ 76.80$; monetary amounts are given in U.S. dollars) per 36 months more than usual care but yielded greater benefits, estimated at 1.302 (95\% $\mathrm{CI}=1.112-1.423)$ QALYs. The ICER per QALY was estimated at $\$ 53.50$ (95\% CI $=\$ 51.60-\$ 54.00$; Table 5).

\section{Discussion}

To our knowledge, this is the first long-term (36 months) controlled, prospective, clinical trial performed in a primary health care setting in a developing country that assessed the economic cost and cost-effectiveness of a pharmaceutical care program for elderly diabetic and hypertensive patients. The evaluation of the economic cost and cost-effectiveness of health care interventions is important in order to justify the viability of implementing new interventions, principally in developing countries where economic resources for public health care services are scarce. To assess the effect of an intervention on costeffectiveness, long-term studies such as the present study are superior to short-term studies because the patients are exposed to factors of everyday living, such as noncompliance and the development of new risk factors, for a longer period of time.

The present results indicate that a pharmaceutical care program did not add significant economic expenditures to health care and had an acceptable ICER per QALY of $\$ 53.50$. Pharmaceutical care significantly improved the clinical parameters evaluated in the present study, which included SBP, DBP, fasting blood glucose, Alc, LDL cholesterol, and the 10-year risk assessment for coronary heart disease risk. The usual care provided at the PHCU showed no improvement in clinical effectiveness for these parameters.

The results of the present study suggest that even in a developing country, introducing pharmaceutical care at the primary health care level is economically viable because it did not add significant direct costs over usual care yet yielded significantly better outcomes. Previous studies also found that introducing pharmaceutical care in the management of diabetic and hypertensive patients added little to direct economic costs and, in some cases, even reduced total direct medical costs. Okamoto and Nakahiro (2001) reported that total direct health care costs were not different when clinical pharmacists were added to help in the management of hypertensive patients (\$521.44 $\pm \$ 438.30$ in the pharmacist-managed hypertension clinical group vs. $\$ 520.91 \pm \$ 387.21$ in the physician clinical group, $P=0.99) .{ }^{14}$ The Asheville Project showed that diabetic patients who received care from a community pharmacist had a $\$ 1,200$ reduction of their mean total direct medical costs while maintaining clinically meaningful improvements in their 
Economic Evaluation of a Pharmaceutical Care Program for Elderly Diabetic and Hypertensive Patients in Primary Health Care: A 36-Month Randomized Controlled Clinical Trial

TABLE 3 Direct Health Care Costs During Study Period (36 Months)

\begin{tabular}{|c|c|c|c|c|c|}
\hline \multirow{2}{*}{$\begin{array}{l}\text { Variable } \\
\text { Mean general practitioner appointment cost per patient, \$ (SD) }\end{array}$} & \multicolumn{2}{|c|}{ Intervention Group $(\mathbf{n}=97)$} & \multicolumn{2}{|c|}{ Control Group $(\mathrm{n}=97)$} & \multirow{2}{*}{$\frac{P \text { Value }^{\mathrm{a}, \mathrm{b}}}{<0.001}$} \\
\hline & 20.0 & $(5.6)$ & 15.2 & $(2.6)$ & \\
\hline Mean specialist appointment cost per patient, \$ (SD) & 1.6 & $(2.8)$ & 0.9 & $(2.6)$ & 0.011 \\
\hline Mean nurse appointment cost per patient, \$ (SD) & 23.5 & $(0.7)$ & 23.4 & $(0.3)$ & 0.758 \\
\hline Mean pharmacist appointment cost per patient, \$ (SD)c & 3.9 & $(0.1)$ & & & \\
\hline Mean emergency department visit cost per patient, \$ (SD) & 0.4 & $(0.9)$ & 0.6 & $(1.7)$ & $<0.001$ \\
\hline Mean drug cost per patient, \$(SD) & 232.4 & $(51.6)$ & 172.1 & $(44.0)$ & 0.181 \\
\hline Mean total health care cost per patient, \$ (SD) & 281.8 & $(49.7)$ & 212.2 & $(43.5)$ & 0.089 \\
\hline Total difference, \$ (SD) & 69.6 & $(7.9)$ & & & \\
\hline \multicolumn{6}{|c|}{$\begin{array}{l}\text { Note: Monetary values are presented in U.S. dollars. } \\
\text { aIndependent-sample Student t-tests were used. } \\
{ }^{2} P<0.05 \text { was considered statistically significant. } \\
\text { cPatients enrolled in the control group did not receive pharmacist appointments. } \\
\text { SD=standard deviation. }\end{array}$} \\
\hline
\end{tabular}

Alc over a 5-year follow-up period. ${ }^{16}$ The Diabetes Ten City Challenge showed that diabetic patients who received care from community pharmacists had a $\$ 1,079$ reduction of their mean total direct medical costs per patient per year. ${ }^{17}$

The pharmaceutical care program in our study demonstrated an acceptable cost-effectiveness ratio. Other studies also found favorable cost-effectiveness ratios for pharmaceutical care in the management of diabetes and hypertension. The pharmacist-managed hypertension group had a better costeffectiveness ratio than the physician-managed general medical clinical group ( $\$ 27.00$ vs. $\$ 193.00$ for SBP readings; $\$ 48.00$ vs. $\$ 151.00$ for DBP readings) in the Okamoto and Nakahiro study. ${ }^{14}$ Correr et al. (2009) found a cost of $\$ 37.62$ per patient per year to reduce $1 \%$ of their Alc levels. ${ }^{23}$

Other aspects of the cost-effectiveness of pharmaceutical care must be considered. The robust improvement of clinical parameters achieved with pharmaceutical care can provide substantial health care savings for diabetic and hypertensive patients. For example, Houle et al. (2012) estimated that a mean 5.6 millimeter of mercury $(\mathrm{mmHg})$ reduction of SBP in diabetic and hypertensive patients who received pharmacist-managed hypertension services can save $\$ 255.80$ per patient per year. ${ }^{15}$ Extrapolation of the results of Houle et al. to the results of this study gives an estimated cost savings of $\$ 1,050.60$ per patient per year because pharmaceutical care program patients in the present study had a mean $23.0 \mathrm{mmHg}$ reduction of SBP. Wagner et al. (2001) reported a $\$ 944.00$ reduction to $\$ 1,309.00$ per patient per year for each $1 \%$ reduction of Alc levels. ${ }^{35}$ In the present study, patients enrolled in the pharmaceutical care group showed a mean 0.7 reduction of Alc levels, yielding a $\$ 660.80$ reduction to $\$ 916.30$ per patient per year.

Similar to other studies, the present study also found that patients who received usual care had a lower consumption of some health care services, such as general practitioner appointments, specialist appointments, and medications com- pared with patients who received pharmaceutical care. These results can be attributed to the clinical inertia of usual care. ${ }^{36,37}$ Previous studies indicated that physicians involved in usual care were satisfied with their patients' blood pressure, fasting blood glucose, and cholesterol levels and did not initiate or intensify medications or follow-up, even when it was indicated. ${ }^{36,37}$ The addition of a pharmacist to the health care team can improve the possibility of achieving desired clinical outcomes through the identification and resolution of drug therapy problems. ${ }^{18,19}$ The identification and resolution of drug therapy problems increase the consumption of some health care services and drugs. ${ }^{14-16}$ For example, in the present study, several patients had elevated LDL cholesterol levels when considering their 10-year risk score for coronary heart disease, but these patients were not using a statin at baseline. Every patient who was enrolled in the pharmaceutical care group and presented elevated LDL cholesterol levels initiated the use of statins during the study, whereas many patients who were enrolled in the usual care group did not start the use of statins. Depending on the drug therapy problem identified, the pharmacist needed to refer the patient to a general practitioner or specialist to resolve the problem, and these activities increased the number of appointments with these professionals in the pharmaceutical care group. However, the expenditures associated with this higher consumption of some health care services by patients who were enrolled in the pharmaceutical care group were very low when considering the robust improvement of clinical outcomes achieved by this kind of intervention.

Pharmacist salaries have been a source of concern for providers when considering the implementation of pharmaceutical care programs ${ }^{38}$ However, the results of the present study and previous studies suggest that the costs of introducing a pharmacist to the health care team have no significant impact. In the present study, each pharmacist appointment cost $\$ 0.70$, which added a cost of $\$ 1.40$ per patient per year when 
Economic Evaluation of a Pharmaceutical Care Program for Elderly Diabetic and Hypertensive Patients in Primary Health Care: A 36-Month Randomized Controlled Clinical Trial

TABLE 4 Clinical Outcome Changes During Study Period (36 Months)

\begin{tabular}{|c|c|c|c|c|c|c|}
\hline \multirow[b]{2}{*}{ Variable } & \multicolumn{2}{|c|}{ Intervention Group $(\mathbf{n}=97)$} & \multicolumn{3}{|c|}{ Control Group $(\mathbf{n}=97)$} & \multirow{2}{*}{$\begin{array}{c}\text { Difference } \\
\text { Between } \\
\text { Groups, DID } \\
P \text { Value } \\
\end{array}$} \\
\hline & $\begin{array}{l}\text { Change During } \\
\text { Study Period }\end{array}$ & $P$ Value ${ }^{\mathrm{a}}$ & \multicolumn{2}{|c|}{$\begin{array}{l}\text { Change During } \\
\text { Study Period }\end{array}$} & $P$ Value ${ }^{\mathrm{a}}$ & \\
\hline SBP (mmHg), mean (95\% CI) & $-23.0(-26.4$ to -19.6$)$ & $<0.001^{\mathrm{b}}$ & -0.4 & $(-3.1$ to 2.3$)$ & 0.765 & $<0.001^{b}$ \\
\hline DBP $(\mathrm{mmHg})$, mean $(95 \% \mathrm{CI})$ & $-14.8 \quad(-17.7$ to -11.9$)$ & $<0.001^{b}$ & -1.9 & $(-3.7$ to 0.0$)$ & 0.055 & $<0.001^{b}$ \\
\hline Fasting glucose $(\mathrm{mg} / \mathrm{dL})$, mean $(95 \% \mathrm{CI})$ & $-27.2(-35.7$ to -18.6$)$ & $<0.001^{\mathrm{b}}$ & 1.1 & $(-3.2$ to 5.4$)$ & 0.615 & $<0.001^{\mathrm{b}}$ \\
\hline Hemoglobin Alc (\%), mean $(95 \%$ CI) & $(-0.9$ to -0.6$)$ & $<0.001^{\mathrm{b}}$ & 0.0 & $(-0.1$ to 0.1$)$ & 0.885 & $<0.001^{\mathrm{b}}$ \\
\hline LDL cholesterol $(\mathrm{mg} / \mathrm{dL})$, mean $(95 \% \mathrm{CI})$ & $-10.4 \quad(-15.8$ to 0.8$)$ & $<0.001^{\mathrm{b}}$ & 2.8 & $(-0.8$ to 3.7$)$ & 0.522 & $<0.001^{\mathrm{b}}$ \\
\hline $\begin{array}{l}\text { 10-year risk assessment for coronary heart disease } \\
(\%) \text {, mean }(95 \% \mathrm{CI})\end{array}$ & $(-3.4$ to -1.3$)$ & $<0.001^{b}$ & 0.0 & $(-0.2$ to 2.1$)$ & 0.754 & $<0.001^{\mathrm{b}}$ \\
\hline \multicolumn{7}{|c|}{$\begin{array}{l}\text { andependent-sample Student t-tests were used. } \\
{ }^{b} P<0.05 \text { was considered statistically significant. } \\
\text { cOnly patients with a diagnosis of diabetes underwent this exam. } \\
{ }^{d} 10 \text {-year risk assessment for coronary heart disease was performed using the Framingham scoring method. }{ }^{32} \\
C I=\text { confidence interval; } D B P=\text { diastolic blood pressure; } D I D=\text { difference in differences test; } L D L=\text { low-density lipoprotein; } m g / d L=\text { milligram per deciliter; } \\
m m H g=\text { millimeter of mercury; } S B P=\text { systolic blood pressure. }\end{array}$} \\
\hline
\end{tabular}

considering a mean of 2 appointments per year. Correr et al. found that each pharmacist appointment cost $\$ 0.09$ in a pharmaceutical care program performed with Brazilian community pharmacies, with a cost of $\$ 0.99$ per patient per year when considering 11 appointments per year. ${ }^{23}$ The expenditures for including clinical pharmacist services in primary health care are only a small portion of overall health care costs.

\section{Limitations}

The present study was long term (36 months), and the number of appointments per patient in the intervention and control groups was similar (a difference of 2 appointments per year between the intervention and control groups), thus minimizing potential bias caused by the Hawthorne effect. Cooper et al. (2001) reported that patients show improvement over 1 to 6 months follow-up because of the positive psychological effect of being observed or monitored (i.e., the Hawthorne effect) and rebound to previous levels after 6 months. ${ }^{39}$ The present study was the first to evaluate the cost-effectiveness ratio of a wide range of clinical parameters, which may be important for policymakers when assessing the viability of introducing pharmaceutical care to primary health care.

Despite these advantages, the present study has some limitations that should be acknowledged. Our study considered only direct health care costs in the analysis, so we did not assess the economic cost and cost-effectiveness ratio of indirect health care costs. The number of pharmacists who performed pharmaceutical care was small, and they received previous training that is not offered to all pharmacists who work at the primary health care level. Therefore, care must be taken when generalizing these results to all pharmacists. Our study was also only performed in $1 \mathrm{PHCU}$, so future multicenter studies with larger

\section{TABLE 5 Simulated Costs and Clinical Effectiveness over 36 Months}

\begin{tabular}{|c|c|c|c|}
\hline Variable & $\begin{array}{l}\text { Expected } \\
\text { Population } \\
\text { Mean }\end{array}$ & $\begin{array}{c}\text { Simulated } \\
\text { 5th centile } \\
\text { (Lower Limit) }\end{array}$ & $\begin{array}{c}\text { Simulated } \\
\text { 95th centile } \\
\text { (Upper Limit) }\end{array}$ \\
\hline \multicolumn{4}{|l|}{ Cost analysis, \$ } \\
\hline Costs of control group & 212.2 & 175.1 & 247.2 \\
\hline Costs of intervention group & 281.8 & 232.5 & 324.0 \\
\hline Incremental costs & 69.6 & 57.4 & 76.8 \\
\hline \multicolumn{4}{|l|}{ QALY analysis } \\
\hline QALYs in control group & 0.108 & 0.089 & 0.187 \\
\hline QALYs in intervention group & 1.410 & 1.201 & 1.610 \\
\hline Incremental QALYs & 1.302 & 1.112 & 1.423 \\
\hline ICER, \$ & 53.5 & 51.6 & 54.0 \\
\hline
\end{tabular}

sample populations are needed to better generalize the results. Nevertheless, the data presented here on the economic cost and cost-effectiveness ratio of pharmaceutical care in the management of elderly diabetic and hypertensive patients at the primary health care level in a developing country are important and will help policymakers in their decision-making process to reduce the economic burden caused by these diseases.

\section{Conclusions}

Pharmaceutical care did not significantly increase total direct health care costs, yet significantly improved health outcomes were seen. The mean ICER per QALY gained suggests that providing pharmaceutical care is a cost-effective option. Policymakers of developing countries may consider our findings in their decision-making process to reduce the economic burden caused by diabetes and hypertension in the elderly population. 


\section{Authors}

PAULO ROQUE OBRELI-NETO, PhD, is a Postdoctoral Student; ANDRÉ DE OLIVEIRA BALDONI, PhD, is Professor; and LEONARDO REGIS LEIRA PEREIRA, PhD, is Professor, Department of Pharmaceutical Sciences, Faculty of Pharmaceutical Sciences of Ribeirao Preto, University of Sao Paulo, Ribeirao Preto, Sao Paulo, Brazil. SRECKO MARUSIC, MD, is Professor, Department of Clinical Pharmacology, University Hospital Dubrava, Zagreb, Croatia; CAMILO MOLINO GUIDONI, PhD, is Professor, Department of Pharmaceutical Sciences, State University of Londrina, Londrina, Parana, Brazil; ROGÉRIO DIAS RENOVATO, PhD, is Professor, Department of Nursing, Universidade Estadual do Mato Grosso do Sul, Dourados, Mato Grosso do Sul, Brazil; DIOGO PILGER, PhD, is Professor, Departmento do Medicamento, Universidade Federal da Bahia, Salvador, Brazil; and ROBERTO KENJI NAKAMURA CUMAN, PhD, is Professor, Pharmacology and Therapeutics, State University of Maringa, Maringa, Brazil.

AUTHOR CORRESPONDENCE: Paulo Roque Obreli-Neto, PhD, Department of Pharmaceutical Sciences, Faculty of Pharmaceutical Sciences of Ribeirao Preto, University of Sao Paulo (USP), Ribeirao Preto, Sao Paulo, Brazil 14096-380. Tel.: +55.16.3633.1941;

E-mail:paulorobreli@yahoo.com.br.

\section{DISCLOSURES}

The authors report no conflicts of interest regarding this study. No separate funding was obtained for this study.

Study concept and design were contributed by Obreli-Neto and Cuman. Obreli-Neto had primary responsibility for data collection; data interpretation was primarily the work of Obreli-Neto, Leira, Guidoni, Baldoni, Marusic, Renovato, Pilger, and Cuman. The manuscript was written primarily by Obreli-Neto, with assistance from Marusic, Guidoni, Leira, Baldoni, and Cuman, and was revised by Renovato, Baldoni, Guidoni, Leira, Pilger, and Marusic.

\section{REFERENCES}

1. International Diabetes Federation. IDF Diabetes Atlas. 6th ed. Brussels, Belgium: International Diabetes Federation; 2013. Available at: http://www.idf. org/sites/default/files/EN_6E_Atlas_Full_0.pdf. Accessed December 8, 2014.

2. Kearney PM, Whelton M, Reynolds K, Muntner P, Whelton PK, He J. Global burden of hypertension: analysis of worldwide data. Lancet. 2005;365(9455):217-23.

3. Stark Casagrande S, Fradkin JE, Saydah SH, Rust KF, Cowie CC. The prevalence of meeting Alc, blood pressure, and LDL goals among people with diabetes, 1988-2010. Diabetes Care. 2013;36(8):2271-79. Available at: http://care.diabetesjournals.org/content/36/8/2271.full.pdf+html. Accessed December 8, 2014.

4. Pereira M, Lunet N, Azevedo A, Barros H. Differences in prevalence, awareness, treatment and control of hypertension between developing and developed countries. J Hypertens. 2009;27(5):963-75.

5. Moreira GC, Cipullo JP, Martin JF, et al. Evaluation of the awareness, control and cost-effectiveness of hypertension treatment in a Brazilian city: populational study. J Hypertens. 2009;27(9):1900-07.

6. Lachin JM, Orchard TJ, Nathan DM; DCCT/EDIC Research Group. Update on cardiovascular outcomes at 30 years of the diabetes control and complications trial/epidemiology of diabetes interventions and complications study. Diabetes Care. 2014;37(1):39-43. Available at: http://care.diabetesjournals.org/content/37/1/39.full.pdf+html. Accessed December 8, 2014.
7. de Boer IH; DCCT/EDIC Research Group. Kidney disease and related findings in the diabetes control and complications trial/epidemiology of diabetes interventions and complications study. Diabetes Care. 2014;37(1):24-30. Available at: http://care.diabetesjournals.org/content/37/1/24.full.pdf+html. Accessed December 8, 2014.

8. Stratton IM, Adler AI, Neil HA, et al. Association of glycaemia with macrovascular and microvascular complications of type 2 diabetes (UKPDS 35): prospective observational study. BMJ. 2000;321(7258):405-12. Available at: http://www.ncbi.nlm.nih.gov/pmc/articles/PMC27454/pdf/405.pdf. Accessed December 8, 2014.

9. Adler AI, Stratton IM, Neil HA, et al. Association of systolic blood pressure with macrovascular and microvascular complications of type 2 diabetes (UKPDS 36): prospective observational study. BMJ. 2000;321(7258):412-19. Available at: http://www.ncbi.nlm.nih.gov/pmc/articles/PMC27455/pdf/412. pdf. Accessed December 8, 2014.

10. Nichols GA, Joshua-Gotlib S, Parasuraman S. Independent contribution of Alc, systolic blood pressure, and LDL cholesterol control to risk of cardiovascular disease hospitalizations in type 2 diabetes: an observational cohort study. J Gen Intern Med. 2013;28(5):691-97. Available at: http://www. ncbi.nlm.nih.gov/pmc/articles/PMC3631078/pdf/11606_2012_Article_2320. pdf. Accessed December 8, 2014.

11. Menzin J, Korn JR, Cohen J, et al. Relationship between glycemic control and diabetes-related hospital costs in patients with type 1 or type 2 diabetes mellitus. J Manag Care Pharm. 2010;16(4):264-75. Available at: http://www. amcp.org/data/jmcp/264-275.pdf.

12. Lloyd-Jones D, Adams R, Carnethon M, et al. Heart disease and stroke statistics-2009 update: a report from the American Heart Association Statistics Committee and Stroke Statistics Subcommittee. Circulation. 2009;119(3):480-86. Available at: http://circ.ahajournals.org/content/119/3/480.full.pdf+html. Accessed December 8, 2014.

13. Hepler CD, Strand LM. Opportunities and responsibilities in pharmaceutical care. Am J Hosp Pharm. 1990;47(3): 533-43.

14. Okamoto MP, Nakahiro RK. Pharmacoeconomic evaluation of a pharmacist-managed hypertension clinic. Pharmacotherapy. 2001;21(11):1337-44.

15. Houle SK, Chuck AW, McAlister FA, Tsuyuki RT. Effect of a pharmacistmanaged hypertension program on health system costs: an evaluation of the Study of Cardiovascular Risk Intervention by Pharmacists-Hypertension (SCRIP-HTN). Pharmacotherapy. 2012;32(6):527-37.

16. Cranor CW, Bunting BA, Christensen DB. The Asheville Project: longterm clinical and economic outcomes of a community pharmacy diabetes care program. J Am Pharm Assoc (2003). 2003;43(2):173-84.

17. Fera T, Bluml BM, Ellis WM. Diabetes Ten City Challenge: final economic and clinical results. J Am Pharm Assoc (2003). 2009;49(3):383-91.

18. Aguiar PM, Balisa-Rocha BJ, Brito GC, Lyra DP Jr. Pharmaceutical care program for elderly patients with uncontrolled hypertension. J Am Pharm Assoc (2003). 2012;52(4):515-18.

19. Lee JK, Grace KA, Taylor AJ. Effect of a pharmacy care program on medication adherence and persistence, blood pressure, and low-density lipoprotein cholesterol: a randomized controlled trial. JAMA. 2006;296(21):2563-71. Available at: http://jama.jamanetwork.com/article. aspx?articleid=204402. Accessed December 8, 2014.

20. Lee VW, Yi PT, Kong KW, Chan PK, Kwok FL. Impact of pharmacy outreach services on blood pressure management in the elderly community of Hong Kong. Geriatr Gerontol Int. 2013;13(1):175-81.

21. Simpson SH, Majumdar SR, Tsuyuki RT, et al. Effect of adding pharmacists to primary care teams on blood pressure control in patients with type 2 diabetes: a randomized controlled trial. Diabetes Care. 2011;34(1):20-26. Available at: http://care.diabetesjournals.org/content/34/1/20.full.pdf+html. Accessed December 8, 2014. 
22. Chung N, Rascati K, Lopez D, Jokerst J, Garza A. Impact of a clinical pharmacy program on changes in hemoglobin Alc, diabetes-related hospitalizations, and diabetes-related emergency department visits for patients with diabetes in an underserved population. J Manag Care Pharm. 2014;20(9);914-19. Available at: http://www.amcp.org/WorkArea/ DownloadAsset.aspx?id=18468.

23. Correr CJ, Pontarolo R, Wiens A, et al. [Economic evaluation of pharmacotherapeutic follow-up in type 2 diabetes mellitus patients in community pharmacies]. Arq Bras Endocrinol Metabol. 2009;53(7):825-33. [Article in Portuguese]. Available at: http://www.scielo.br/pdf/abem/v53n7/06.pdf. Accessed December 8, 2014.

24. Borges AP, Guidoni CM, Freitas Od, Pereira LR. Economic evaluation of outpatients with type 2 diabetes mellitus assisted by a pharmaceutical care service. Arq Bras Endocrinol Metabol. 2011;55(9):686-91. Available at: http:// www.scielo.br/pdf/abem/v55n9/03.pdf. Accessed December 8, 2014.

25. Brasil. República Federativa do Brasil. Lei n. 8080, 19 de setembro de 1990. Dispõe sobre as condições para a promoção, proteção e recuperação da saúde, a organização e o funcionamento dos serviços correspondentes e dá outras providências. Available at: http://portal.in.gov.br/. Accessed December 8, 2014.

26. Brasil. República Federativa do Brasil. Lei n. 8142, de 28 de dezembro de 1990. Dispõe sobre a participação da comunidade na gestão do Sistema Único de Saúde (SUS) e sobre as transferências intergovernamentais de recursos financeiros na área da saúde e dá outras providências. Available at: http://portal.in.gov.br/. Accessed December 8, 2014.

27. Sociedade Brasileira de Cardiologia-SBC; Sociedade Brasileira de Hipertensão-SBH; Sociedade Brasileira de Nefrologia-SBN. [IV Brazilian Guidelines in Arterial Hypertension]. Arq Bras Cardiol. 2007;89(3):e24-79. [Article in Portuguese]. Available at: http://www.scielo.br/pdf/abc/v82s4/03. pdf. Accessed December 8, 2014.

28. Brazilian Society of Diabetes. Brazilian Society of Diabetes' Guidelines 2009. Itapevi, SP: Araújo Silva Farmacêutica; 2009.

29. Cipolle RJ, Strand LM, Morley PC. Pharmaceutical Care Practice: The Clinician's Guide. New York: McGraw-Hill; 2004.
30. Diabetes Control and Complication Trials Research Group. Lifetime benefits and costs of intensive therapy as practiced in Diabetes Control and Complications Trial. JAMA. 1996;276(17):1409-15.

31. Shin AY, Porter PJ, Wallace MC, Naglie G. Quality of life of stroke in younger individuals. Utility assessment in patients with arteriovenous malformations. Stroke. 1997;28(12):2395-99. Available at: http://stroke.ahajournals.org/content/28/12/2395.long. Accessed December 8, 2014.

32. Wolf PA, D'Agostino RB, O'Neal MA, et al. Secular trends in stroke incidence and mortality. The Framingham Study. Stroke. 1992;23(11):1551-55. Available at: http://stroke.ahajournals.org/content/23/11/1551.long. Accessed December 8, 2014.

33. Tsevat J, Goldman L, Soukup JR, et al. Stability of time-tradeoff utilities in survivors of myocardial infarction. Med Decis Making. 1993;13(2):161-65.

34. Nease RF Jr, Kneeland T, O'Connor GT, et al. Variation in patient utilities for outcomes of the management of chronic stable angina. Implications for clinical practice guidelines. Ischemic Heart Disease Patient Outcomes Research Team. JAMA. 1995;273(15):1185-90.

35. Wagner EH, Sandhu N, Newton KM, et al. Effect of improved glycemic control on health care costs and utilization. JAMA. 2001;285(2):182-89. Available at: http://jama.jamanetwork.com/article.aspx?articleid=193448. Accessed December 8, 2014.

36. Phillips LS, Branch WT, Cook CB, et al. Clinical inertia. Ann Intern Med. 2001;135(9):825-34.

37. Byrnes PD. Why haven't I changed that? Therapeutic inertia in general practice. Aust Fam Physician. 2011;40(1-2):24-28. Available at: http://www. racgp.org.au/download/documents/AFP/2011/JanFeb/201101byrnes.pdf. Accessed December 8, 2014.

38. Rothman RL, So SA, Shin J, et al. Labor characteristics and program costs of a successful diabetes disease management program. Am J Manag Care. 2006;12(5):277-83. Available at: http://www.internetgroup.ca/clientnet_new/docs/Labor\%20Characteristics\%20and\%20Program\%20Costs.pdf. Accessed December 8, 2014.

39. Cooper H, Booth K, Fear S, Gill G. Chronic disease patient education: lessons from meta-analyses. Patient Educ Couns. 2001;44(2):107-17. 